. Thompson, J. S. Johnson, L. M. \& Grunstein, M. Mol. Cell. Biol. 14, 446-455 (1994).

8. Marcand, S., Buck, S. W., Moretti, P., Gilson, E. \& Shore, D. Genes Dev. 10, 1297-1309 (1996).

9. Maillet, L et al. Genes Dev. 10, 1796-1811 (1996).

10. Maillet, L. et al. EMBO Rep. 2, 203-210 (2001).

11. Gotta, M. et al. J. Cell Biol. 134, 1349-1363 (1996).
12. Heun, P., Laroche, T. Raghuraman, M. K. \& Gasser, S. M. J. Cell Biol. 152, 385-400 (2001).

13. Tham, W. H., Wyithe, J. S., Ferrigno, P. K., Silver, P. A. \&

Zakian, V. A. Mol. Cell 8, 189-199 (2001).

14. Shore, D. Science 281, 1818-1819 (1998).

15. Mishra, K. \& Shore, D. Curr. Biol. 9, 1123-1126 (1999).

16. Galy, V. et al. Nature 403, 108-112 (2000).
17. Feuerbach F et al. Nature Cell Biol 4, 214-221 (2002).

18. Heun, P., Laroche, T., Shimada, K., Furrer, P. \& Gasser, S. M. Science 294, 2181-2186 (2001).

19. Andrulis, E. D., Neiman, A. M., Zappulla, D. C. \& Sternglanz, R. Nature 394, 592-595 (1998).

20. Marshall, W. F., Dernburg, A. F., Harmon, B., Agard, D. A. \& Sedat, J. W. Mol. Biol. Cell 7, 825-842 (1996).

\title{
Intervening through interferon
}

One way in which the vesicular stomatitis virus disables its host is by blocking messenger RNA export from the nucleus - a process that is crucial for the livelihood of the cell. To do this, the viral M protein binds and inhibits a key component of the nuclear pore, nucleoporin 98 (Nup98). Enninga and colleagues (Science Express Reports 10.1126/science.1067861) now show that this factor is also the focal point of the cell's counterattack.

Cells respond to viral infection by sending distress signals that recruit, among other things, cytokines of the interferon family (IFN- $\alpha / \beta$ and IFN- $\gamma$ ), but exactly how these molecules lead to the downfall of the virus is multifaceted and incompletely understood. Previous experiments looking at which genes were upregulated by IFN- $\gamma$ highlighted Nup98 as one possible comrade. In the present study, Enninga et al. identified two classic IFN response elements in the promoter region of the cotranscribed nup98 and nup96 genes. They then confirmed that incubation of cells with IFN- $\gamma$ resulted in increased levels of nup96/nup98 mRNA and their corresponding proteins through a Stat1dependent signalling pathway - an effect that was specific to these distinct nucleoporins.

So what is the fate of all this extra protein? Using immunofluorescence microscopy, the authors showed that the extra Nup96 and Nup98 go to where they would normally - the nuclear pore complex and the nuclear interior. More importantly, how does this help the cell cope with infection? Enninga and colleagues predicted that increased levels of Nup98 might saturate the inhibition by M protein by providing enough free Nup98 to do its normal job - mediating mRNA export. This intuitively makes sense, as the region of Nup98 bound by the M protein also contains the motifs through which it binds cellular export receptors. In support of this notion, they found that the normal release of mRNA from
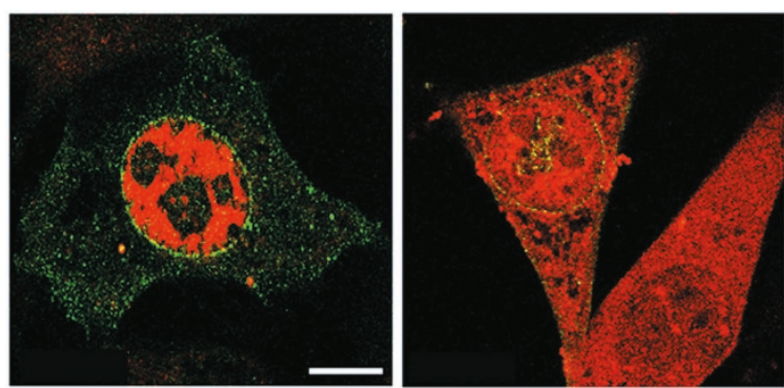

REPRINTED WITH PERMISSION FROM SCIENCE EXPRESS REPORTS 10.1126/SCIENCE.1067861 (C) (2002) AMERICAN ASSOCIATION FOR THE ADVANCEMENT OF SCIENCE.

the nucleus to the cytoplasm of M-protein-expressing cells could be restored by treatment with IFN- $\gamma$ (the figure shows M-expressing cells before (left) and after (right) treatment; mRNA, red, M protein, green; Scale bar represents $7.5 \mu \mathrm{m}$ ).

This does not rule out, however, the possible contributions made by other genes that are upregulated by IFN- $\gamma$. To confirm that Nup96 and Nup98 are indeed the chosen heroes, they asked whether transfection of infected cells with nup96 and nup98 cDNA could bypass the need for IFN- $\gamma$ - it could.

The task ahead, say the authors, is to confirm the mechanism by which increased Nup98 and Nup96 levels reverse viral effects and to see whether this is the only function they have in protecting the cell.

ALISON SCHULDT

\section{News and Views contributions}

The News and Views section provides a forum in which new advances in the field of cell biology, as reported in published papers, can be communicated to a wide audience. Most News and Views pieces are linked to Articles that appear in Nature Cell Biology, but some may focus on papers of exceptional significance that are published elsewhere. Unsolicited contributions will not normally be considered, although prospective authors are welcome to make proposals to the Editor before the paper is published.

As a general guideline, News and Views pieces should be about 1,300 words, with one or two display items (figures, boxes and tables). They should make clear the advance (the 'news') and communicate a sense of excitement, yet provide a critical evaluation of the work in context of the rest of the field. We encourage personal 'views', criticisms and predictions, but authors should not refer to their own work, except in passing.

Detailed guidelines are available on request from cellbio@nature.com and on Nature Cell Biology's Web site (http://cellbio.nature.com). 